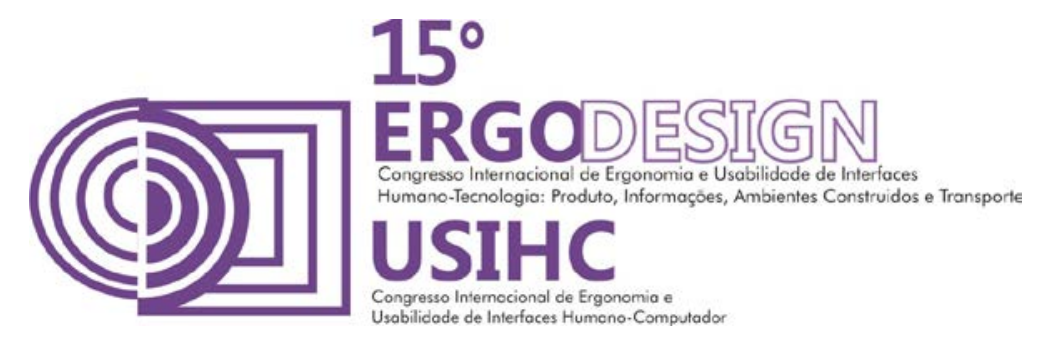

\title{
ERGONOMIZANDO INDÚSTRIAS: UM ESTUDO DO SETOR DE CORTE DE UMA EMPRESA PERNAMBUCANA
}

\author{
BARROS, Bruno (1); \\ VILLAROUCO, Vilma (2); \\ SILVA JUNIOR, José Adilson (3); \\ DUARTE, Geziane (4) \\ (1) Universidade Federal de Pernambuco, Mestre \\ e-mail:barros bruno@hotmail.com \\ (2) Universidade Federal de Pernambuco, Doutora \\ e-mail:villarouco@hotmail.com \\ (3) Universidade Federal de Pernambuco, Bacharel \\ e-mail: silvajunior.adilson@hotmail.com \\ (4) Universidade Federal de Pernambuco, Bacharela \\ e-mail: gezianeduarte@hotmail.com
}

\begin{abstract}
RESUMO
Considerado uma das principais fontes de geração de emprego, devido ao seu quantitativo de empresas formais e informais, a importância econômica do Polo de Confecções do Agreste para o estado de Pernambuco se faz evidente. Neste sentido, foi realizada uma avaliação ergonômica no setor de corte de uma confecção de fardamentos na cidade de Caruaru, Pernambuco, seguindo a Metodologia Ergonômica do Ambiente Construído-MEAC. A avaliação permitiu identificar os índices, níveis, valores e resultados acerca da iluminação, ventilação e aeração, temperatura, vibração, ruído e cor do setor de corte, que quando comparados com as bibliografias, referências, normas e leis existentes, puderam revelar condições físico-ambientais deficientes, as quais podem ser prejudiciais à saúde e segurança dos funcionários do setor de corte da empresa.
\end{abstract}

\begin{abstract}
Considered one of the main sources of employment generation, due to its quantitative formal and informal enterprises, the economic importance of the Wasteland Clothes Pole for the state of Pernambuco is evident. In this sense, an ergonomic evaluation was performed in the making of a sewing uniforms in Caruaru, Pernambuco sector, following the methodology Ergonomic Built Environment-MEAC. The evaluation identified the indices, levels, values and results about the lighting, ventilation and aeration, temperature, vibration, noise and color of the sewing industry, which when compared to the bibliographies, references, standards and existing laws could prove physical conditions disabledenvironment, which can be harmful to health and safety of employees in the sewing company department.
\end{abstract}




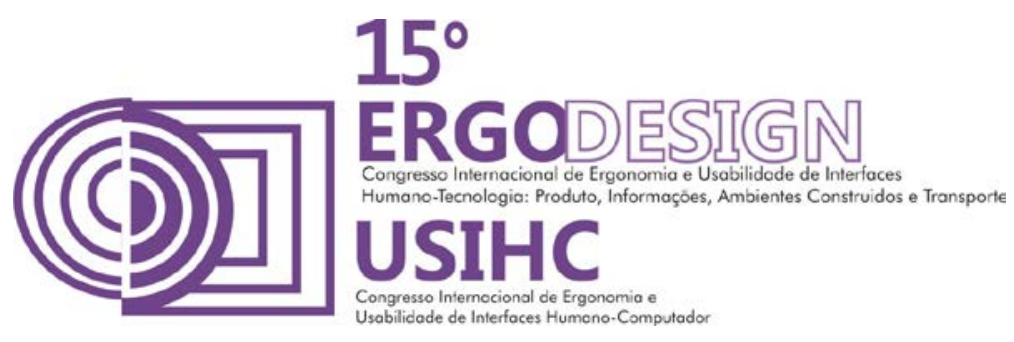

\section{INTRODUÇÃO}

As indústrias de confecções do vestuário e similares representam um quantitativo significativo para a cidade de Caruaru e principalmente para o estado, considerando que segundo o SEBRAE (2012) existiam cerca de 1.666 empresas até o ano de 2002 em todo o estado. Até o ano de 2008, o MTE (2009 apud DIEESE,2010) afirma que as empresas do setor têxtil nos municípios de Caruaru, Toritama e Santa Cruz do Capibaribe, principais cidades do Polo de Confecções do Agreste, totalizavam cerca de 2.030 empresas. As mesmas possuem grande participação na economia do estado assim como, são responsáveis por gerar empregos para homens e mulheres.

Aparentemente, os ambientes de trabalho de uma confecção podem vir a apresentar deficiências em alguns fatores como: ambientes aparentemente pequenos, mal ventilados com pouca iluminação, máquinas amontoadas acarretando circulações estreitas com obstáculos impedindo um fluxo contínuo, equipamentos e elementos de apoio mal distribuídos e condições de trabalhos inadequadas. Reis (2012 apud Aquino et al., 2012), afirma que o setor apresenta um ambiente de trabalho que pode vir a oferecer riscos a saúde do trabalhador, sendo assim, alvo de preocupações.

Sendo assim, a pesquisa buscou realizar uma avaliação ergonômica em um setor de corte de tecido de uma indústria de confecção no município de Caruaru, voltada para a fabricação de roupas profissionais (uniformes). Deste modo, buscou-se aferir os valores de iluminância, ventilação, temperatura, vibração e ruído no ambiente de trabalho dos costureiros, e, por fim, analisar as características cromáticas de todo o setor, para então propor melhorias que possam tornar o ambiente de trabalho adequado às necessidades dos funcionários do mesmo.

\section{FUNDAMENTAÇÃO TEÓRICA}

\subsection{O Mercado Nacional e Local de Confecção}

O município de Caruaru, localizado no Agreste de Pernambuco com área aproximada de 921 $\mathrm{Km}^{2}$ e uma população estimada de 298.501 habitantes, está situada a $140 \mathrm{Km}$ da capital Recife. Devido a sua importância política, econômica e cultural, a mesma é também conhecida por outros nomes como; a "Capital do Agreste", a "Princesa do Agreste" e a "Capital do Forró". Suas principais fontes de renda são; o comércio, destacando-se a Feira de Caruaru, o turismo, tendo como principais pontos na cidade o Alto do Moura e a Feira de Artesanatos, e as indústrias de confecções (IBGE, 2013).

Até o ano de 2002, o SEBRAE (2010) contabilizou cerca de 1.666 indústrias voltadas para a fabricação de artigos do vestuário em geral, no estado de Pernambuco. É importante frisar que esses dados caracterizam o quantitativo de empresas legalizadas que, desde então, tal número de confecções formais vem crescendo não somente no estado, mas especificamente nas cidades em que a produção de roupas e similares faz parte do seu desenvolvimento econômico. Esse crescimento também é observado nas confecções informais que, apesar de não serem legalizadas, participam ativamente da economia do estado. Porém, essa realidade 


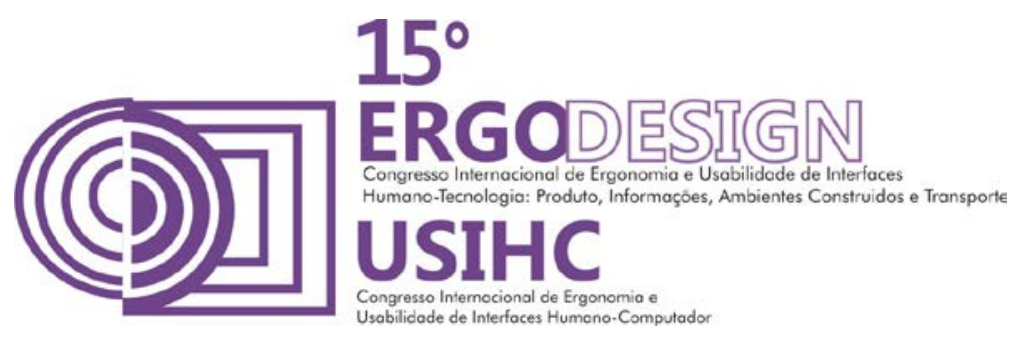

foi alterada devido à popularização dos artigos fabricados no estado, sendo possível observar o crescimento do setor no quantitativo de empresas e consequentemente, no número de novos empregos.

De acordo com o MTE (2009 apud DIEESE, 2010), entre os anos de 2006 a 2008, foi possível observar um crescimento de aproximadamente $13 \%$ dos estabelecimentos formais e $16 \%$ dos trabalhadores do setor têxtil da cidade de Caruaru, apresentando uma média de 59,9\% e $61,9 \%$, respectivamente. Porém, analisando o ano de 2002 e 2008, observa-se o crescimento considerável do número de estabelecimentos industriais voltado para o setor têxtil, sendo que foram contabilizadas no ano de 2008, 2.030 empresas somente nas cidades de Caruaru, Santa Cruz do Capibaribe e Toritama, aonde possivelmente esse quantitativo venha a ser ainda maior com o acréscimo de outras cidades do estado.

No Brasil, o quantitativo de confecções destinadas à fabricação de fardamentos vem crescendo consideravelmente nos últimos anos, chegando a representar uma parcela relevante para a economia do país, e isso se deve possivelmente ao aumento da procura pelos mesmos, seja pelos empresários ou por seus funcionários. A Associação Brasileira de Desenvolvimento Industrial (2010 apud SEBRAE, 2012), afirma que, em 2008, o segmento de uniformes profissionais no Brasil contava com 1.700 empresas e movimentava cerca de $\mathrm{R} \$ 3,5$ bilhões/ano no País. O segmento cresceu mais de $80 \%$ em produção e cerca de $50 \%$ em valor na última década, apesar da falta de regulamentação e da observação de normas técnicas do setor.

\subsection{A Ergonomia do Ambiente Construído}

A Ergonomia do Ambiente Construído ou como também é chamada, Ergonomia Ambiental, tem como preocupação a forma como se dá a integração entre o ser humano e o ambiente, segundo os aspectos sociais, culturais, organizacionais e psicológicos (VASCONCELOS, VILLAROUCO e SORAES, 2009). É importante se conhecer os fatores que fazem parte de um ambiente construído, a fim de propor melhorias que possam vir a beneficiar no bem estar do funcionário e no melhor desempenho de suas atividades.

Com relação à análise de um posto de trabalho, lida (2005) diz que, quando se trata de uma unidade mais simples, onde o ser humano interage apenas com uma máquina, é importante realizar um estudo das interações que acontecem entre o ser humano, a máquina e o ambiente do trabalho. A ergonomia do ambiente construído busca estudar essa relação entre o homem e seu local de trabalho, assim como os equipamentos usados nas atividades nele desenvolvidas, a fim de proporcionar um ambiente adequado às necessidades do seu usuário.

Villarouco e Andreto (2008), afirmam que a diversidade de atividades e diversidade humana se for consideradas, pode segundo as características do ambiente, facilitar ou dificultar a realização das atividades, e que o conceito de ambiente de trabalho não pode ser aplicado totalmente, devido a esses ambientes mudarem segundo seu tipo de atividade, ou seja, tal conceito pode vir a auxiliar na avaliação de ambientes similares.

\subsection{Aspectos Normativos Reguladores do Ambiente}




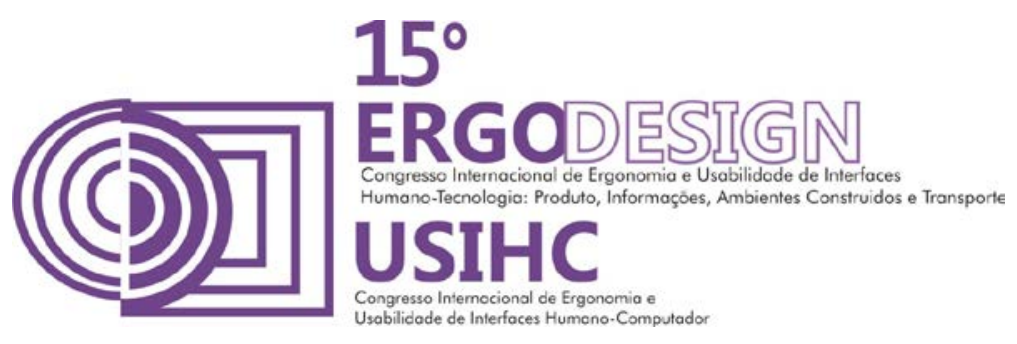

lida (2005), afirma que é importante o uso da iluminação adequada para realização das tarefas, pois se sabe que a iluminância em excesso ou escassez facilita o aparecimento da fadiga visual. Outro problema que pode ocorrer é o ofuscamento, que ocorre com o excesso de luz, janelas ou locais com excesso de brilho, causando uma redução de eficiência visual (Maia 2012).

A NBR5382 estabelece como se deve averiguar a iluminância de interiores em áreas retangulares, por meio da iluminância média sobre um plano horizontal, derivado da iluminação comum. Já a NBR 5413/1992 diz que o índice de iluminância adequado para uma sala de aula deve estar entre 200, 300 e 500Lux. Mas para alunos menores de 40 anos de idade, cuja atividade em sala não requer velocidade e precisão deve ser considerado o valor mais baixo, 200LuX.

O Conforto térmico é um estado mental que reflete a satisfação com o ambiente térmico que envolve a pessoa. Se o balanço de todas as trocas de calor, a que está submetido o corpo, for nulo e a temperatura da pele e suor estiverem dentro de certos limites, pode-se dizer que o homem sente o conforto térmico (ASHRAE, 1985 apud LAMBERT, 1997). O conforto térmico também pode ser o dificultador da realização de atividades, pois além de causar desconfortos existe uma perda de energia maior que em um ambiente em condições térmicas confortáveis.

Para lida (2005), uma zona de conforto térmico apropriada aos padrões brasileiros tem temperatura efetiva entre $20^{\circ}$ e $24^{\circ} \mathrm{C}$, com umidade relativa de 40 a $60 \%$, com a velocidade do ar na ordem $0,2 \mathrm{~m} / \mathrm{s}$ e as diferenças de temperatura em um mesmo ambiente não devem ser maiores a $4^{\circ} \mathrm{C}$. A NR-17 diz que diz que o índice de temperatura efetiva deve estar entre $20^{\circ} \mathrm{e}$ $23^{\circ} \mathrm{C}$ e que a velocidade do ar não deve ser superior a $0,75 \mathrm{~m} / \mathrm{s}$.

No que diz respeito as sensações cromáticas, Stone (2003) afirma que a cor no ambiente pode agir como estímulo, podendo influenciar o humor, a satisfação e a motivação do indivíduo. Determinar a influencia das cores do ambiente sobre o indivíduo pode ser útil para o projeto de ambientes de local de trabalho (STONE 2001).

A Norma ISO 11064-6 indica que as paredes devem ter acabamentos com cores frias, poupando acabamentos escuros ou luminosos em amplas superfícies; a variação de cores e texturas deve existir para favorecer o relaxamento; deve ser evitado grandes contrastes entre mobiliários e equipamentos.

Montenegro (2003) garante que, embora haja quem diga que ventilação e aeração são coisas distintas, não é possível diferencia ventilação de aeração, pois ele define ventilação (ação do vento) como o movimento do ar e aeração como sendo a renovação do ar por meio natural do vento ou de outra coisa. Ainda segundo o mesmo autor, cada individuo precisa de precisa de aproximadamente $30 \mathrm{~m}^{3}$ de ar por hora, é o que registra os estudos dos biólogos.

Ruído é uma combinação de sons com frequências que não seguem leis precisas (ARAÚJO e REGAZZI 2002). Bistafa (2006), diz que o ruído é um som sem harmonia. Para ambos os autores citados o ruído é um som prejudicial ao bem estar dos que têm contato com ele, sendo um condicionante que precisa de ajuste.

O limite de nível de ruído diário em que um indivíduo pode permanecer exposto sem danos a audição é de $80 \mathrm{~dB}(\mathrm{~A})$, caso esse limite seja excedido, há um risco de perda auditiva, ao qual varia de pessoa para pessoa. Nos ambientes de trabalho que superem o nível máximo 


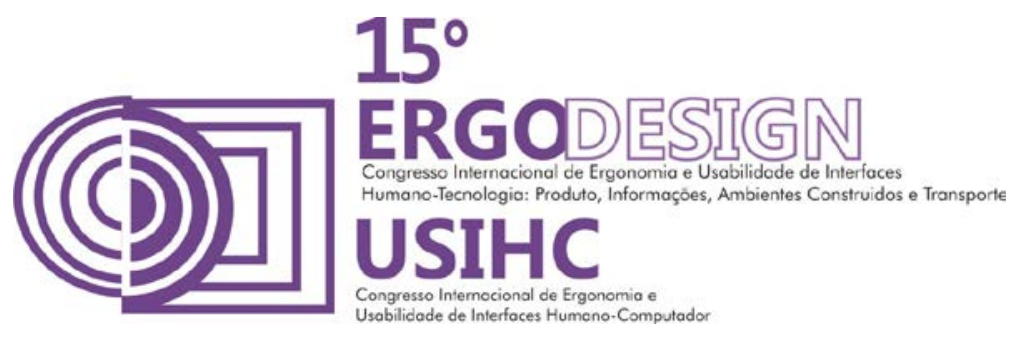

permitido, devem ser feitas intervenções, a fim de reduzir os níveis de ruídos, mas em alguns casos, ainda é necessária a adoção de equipamentos de proteção individual, especificamente, protetores auriculares (BRASIL, 2013b).

Os danos que as vibrações podem provocar ao homem dependem das frequências que compõem as mesmas, sendo as vibrações de baixa frequência (de 1 a $80-100 \mathrm{~Hz}$ ) as mais prejudiciais e as de alta frequência (acima de $100 \mathrm{~Hz}$ ) menos prejudiciais, pois são absorvidas pelo corpo, não gerando ressonância. Desse modo, os problemas mais comuns em decorrência de vibração localizadas são: danos neurológicos, de ordem vascular e osteoarticular e muscular, podendo ocorrer adormecimento leve e intermitente, formigamento ou os dois casos (CONSELHO E SEGURANÇA DO TRABALHO, 2011).

\section{PROCEDIMENTOS METODOLÓGICOS ADOTADOS}

A metodologia utilizada na referente pesquisa foi a MEAC (Metodologia Ergonômica do Ambiente Construído), que é proposta por Villarouco (2009). A seleção desta metodologia seguiu o atendimento de requisitos como consistência cientificamente comprovada e abordagem de aspectos referentes não só aos condicionantes ambientais, como também à percepção dos usuários.

A MEAC é compreendida em quatro etapas analíticas e duas conclusivas, sendo elas: a Análise Global do Ambiente; a Identificação da Configuração do Ambiental; a Avaliação do Ambiente em Uso, Percepção Ambiental do Usuário, Diagnóstico Ergonômico do Ambiente e Proposições Ergonômicas para o Ambiente. Para uma maior compreensão da metodologia utilizada em toda a pesquisa, a seguir são caracterizadas cada uma de suas etapas:

1. Análise Global do Ambiente: A Análise Global do ambiente consiste na fase inicial da pesquisa, onde se tem o primeiro contato com o ambiente estudado, o que possibilita ter ideia da configuração espacial do ambiente e se analisa as atividades desenvolvidas. A partir disso, se percebe os principais problemas e demandas que indicam a necessidade da intervenção. Possibilitando uma visão sistêmica do ambiente a partir do conhecimento dos materiais, do pessoal que usa o ambiente, do desperdício de tempo e equipamentos utilizados, dos fluxos, dos processos e produtos principais, para assim, entender o que é feito e como é feito o ambiente (VILLAROUCO, 2009).

2. Identificação da Configuração Ambiental: Na fase de Identificação da Configuração do Ambiente, é estudada a análise da tarefa para conhecer as condições físico-ambientais. Através do conhecimento do trabalho realizado, das tarefas desenvolvidas, das características que devem conter os postos e estação de trabalho, maquinário, equipamentos e tecnologias utilizadas. (VILLAROUCO, 2007).

3. Avaliação do Ambiente em Uso no Desempenho das Atividades: Na terceira fase Villarouco (2009) recomenda que seja feita uma Avaliação do Ambiente em Uso no desenvolvimento das atividades, para saber o quanto facilitador e dificultador se torna o ambiente no momento da realização das tarefas. Nessa fase, analisa-se o desenvolvimento das atividades focando no espaço construído, com o objetivo de verificar a interferência positiva ou negativa do espaço construído no desempenho das atividades. 


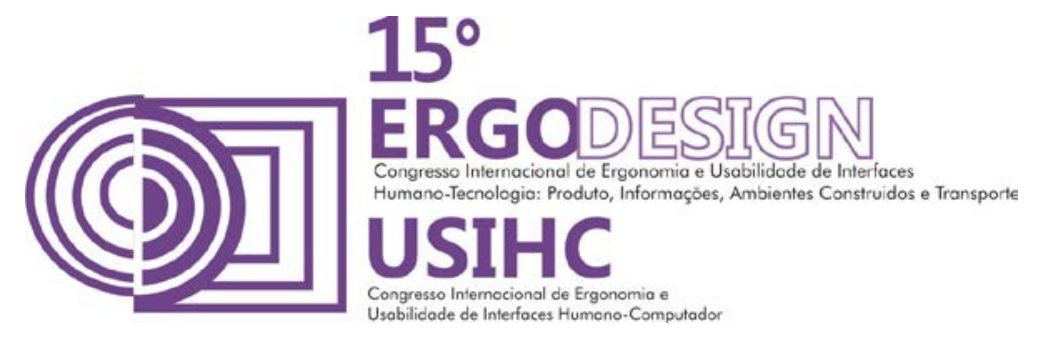

4. Análise da Percepção do Usuário: Na quarta e última fase chamada de Percepção Ambiental, a autora diz que é necessário fazer um estudo da percepção que os usuários têm do ambiente que utiliza. Para se entender melhor a percepção do usuário, é importante utilizar o auxilio da psicologia ambiental como ferramenta auxiliar para identificar as características de caráter mais cognitivo e perceptual.

Por fim, a MEAC é concluída com mais 2 etapas, a 5. Diagnóstico Ergonômico do Ambiente e 6. Proposições Ergonômicas para o Ambiente, as quais irão apresentar os resultados das avaliações e expor recomendações de alteração direcionadas ao ambiente em questão.

\section{DISCUSSÃO E APRESENTAÇÃO DOS RESULTADOS}

A iluminação artificial se dá através de 8 lâmpadas fluorescentes dispostas em fileiras. São poucos os focos de iluminação natural, sendo os mesmos ainda insuficientes para gerar um iluminamento que venha a contribuir com o melhoramento da visibilidade do ambiente na realização de suas atividades. Outro ponto que contribui na deficiência de iluminação natural está no fato de que as maiores aberturas, que permitem maior passagem de luz, estão afastadas dos postos de trabalho das costureiras. (Figura 1).

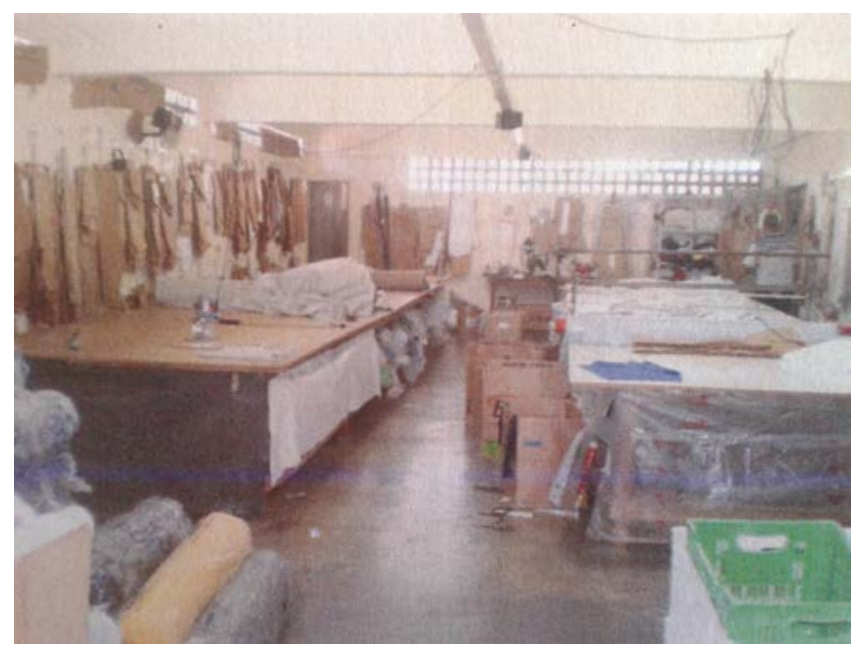

Figura 1: Ambiente de corte no momento da análise

Desse modo, a NBR 5413 determina no item 5.3 .53 a iluminância adequada para os setores da indústria de vestuário, especificamente, para o setor de corte, permanecendo o índice entre 750 a 1500. No entanto, o resultado de iluminância média do salão de corte da empresa, obtido por meio das medições realizadas no local com o luxímetro no período da manhã, é de 402,32 lux, demonstrando um índice de iluminância muito abaixo do valor mínimo determinado pela norma. 


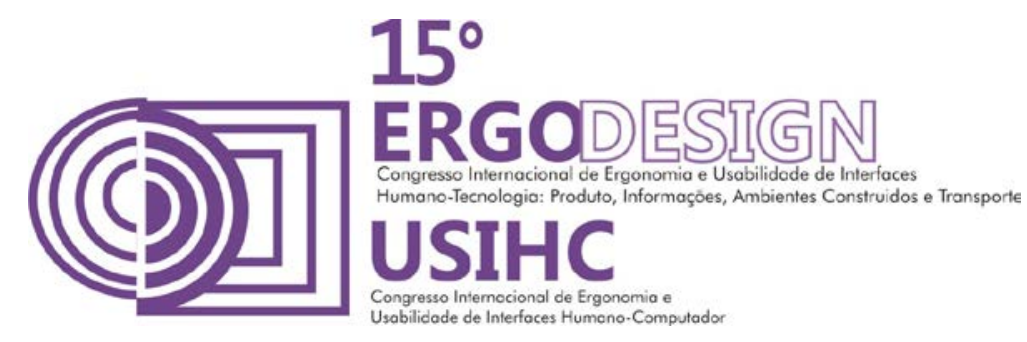

O ruído encontrado no setor de corte se torna maior com a utilização das serras de corte circular e de fita, sendo a de fita a produtora de maior ruído. A medição do nível de ruído no ambiente, no momento de funcionamento da serra circular, captou o nível de 80,0dB; e utilizando a serra de fita (também bastante usada no corte, foi detectado 86,0dB. De acordo com as referências encontradas, o ouvido humano pode estar exposto a um nível de ruído de $80 \mathrm{~dB}$, sem prejuízos à audição. Mesmo considerando que o trabalhador usa os equipamentos de segurança, incluindo os protetores auriculares, o ambiente está propiciando um nível sonoro acima do valor indicado.

A ventilação no setor de corte é comprometida pelas poucas aberturas no ambiente para recebimento de ventilação natural e fechamento das mesmas, feitas pelos próprios funcionários, e pela falta de uso dos dois ventiladores de parede. Após a aferição, vimos uma ventilação próxima ao trabalhador praticamente nula, obteve-se, no centro do ambiente o valor de $0,0 \mathrm{~m} / \mathrm{s}$ de ventilação, já próximo à abertura voltada para a rua, obteve-se $0,6 \mathrm{~m} / \mathrm{s}$.

Na obtenção do nível de vibração recebido pelo usuário do ambiente, foi realizada a medição próxima a este como indica a norma. A vibração no momento em que o usuário utiliza a serra circular foi detectado o valor de 2,5. E, no momento do uso da máquina serra de fita, foi encontrado o valor de 3,4 de vibração.

A medição de temperatura no setor de corte foi dada no centro do ambiente no momento da realização das atividades e em horário em que a incidência do sol é mais intensa na parede principal do ambiente. O resultado da medição foi $30,3^{\circ} \mathrm{C}$. Porém, para as referências encontradas, um ambiente construído ideal deve estar entre $21^{\circ} \mathrm{C}$ a $26^{\circ} \mathrm{C}$, o que não ocorre no ambiente em questão.

As cores utilizadas no ambiente são o branco e o bege, sendo o bege nas paredes do ambiente e o branco nas colunas e teto. De acordo com as referências, cores claras transmitem a sensação de calmaria e amplitude.

Em relação à organização do espaço no setor de corte, o grande problema é que não há um local específico para o estoque de tecido, ficando os rolos de tecido ocupando uma parte significativa do ambiente, deste modo, dificultando o fluxo de pessoas. Existe uma deficiência em não ter um local específico para guardar as modelagens prontas que se encontram penduradas, dificultando o fluxo dos funcionários, assim como as caixas de retalhos que ficam no meio das duas mesas de corte, restringindo a movimentação dos funcionários. 

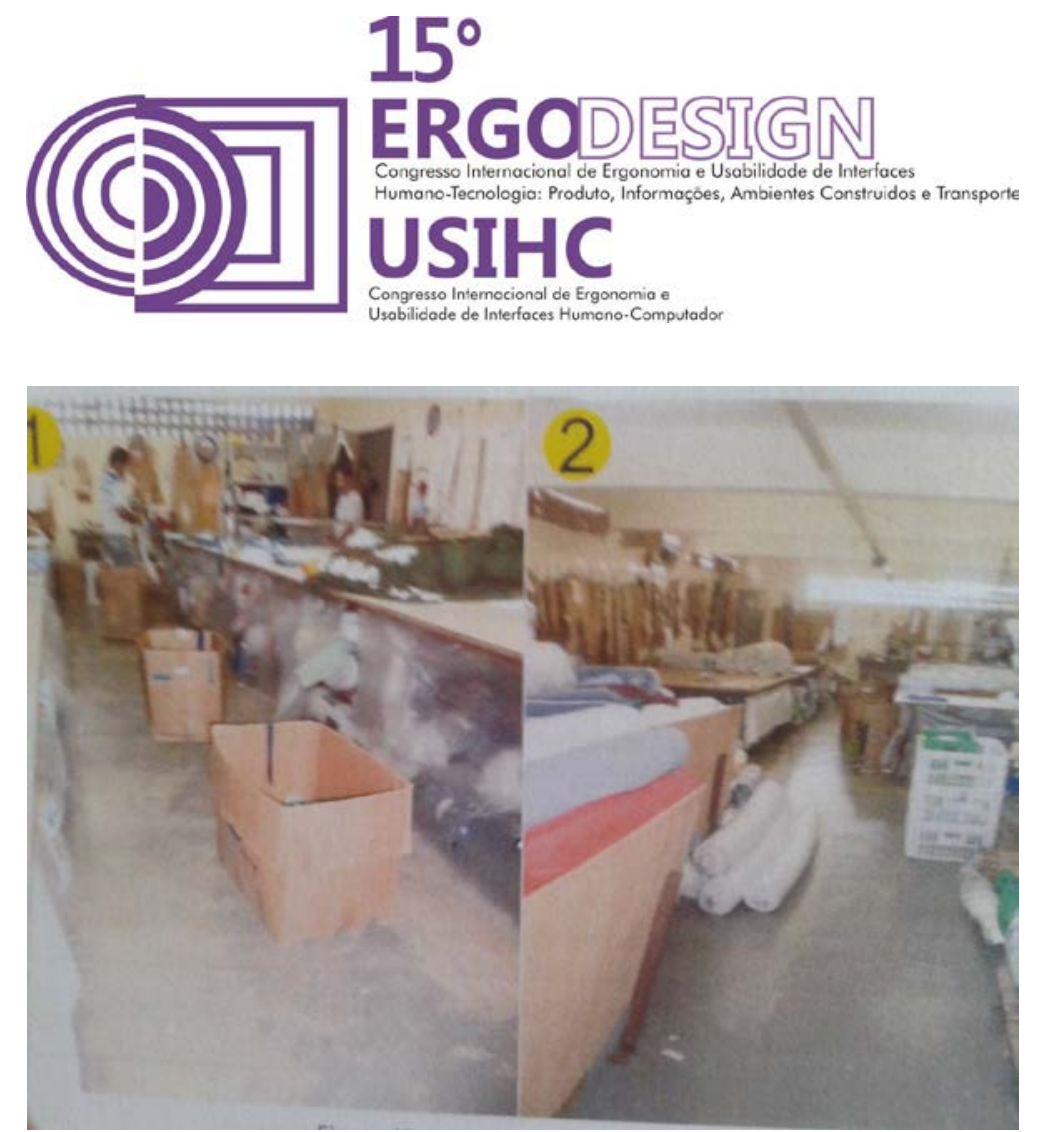

Figura 2: Falta de organização do espaço no momento da análise.

O espaço se encontra desorganizado devido ao crescimento rápido da empresa, tanto em questão de maquinário e equipamentos, quanto de funcionários, ocasionando postos de trabalho com espaços reduzidos e, em alguns casos, inadequados. Em alguns corredores do setor de corte só é possível a circulação de pessoas com o troco lateralizado, assim como em outros ambientes da indústria, como o setor de costura e de expedição, com seus materiais e equipamentos em locais indevidos.

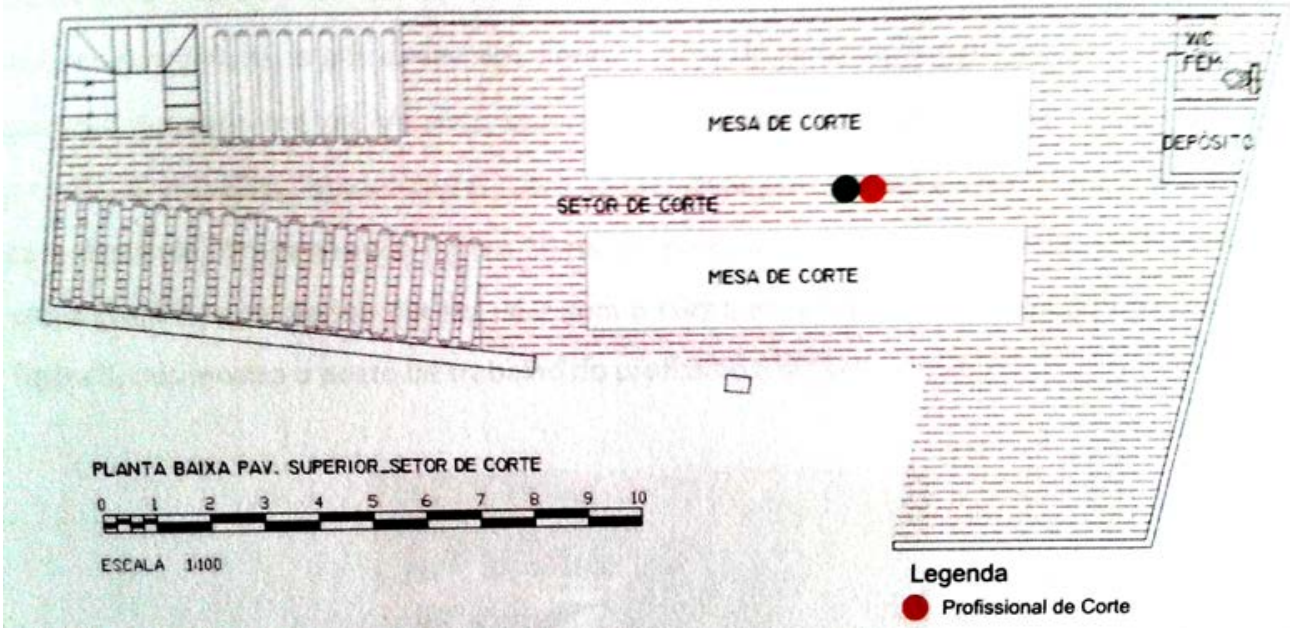

Figura 3: Layout do ambiente 


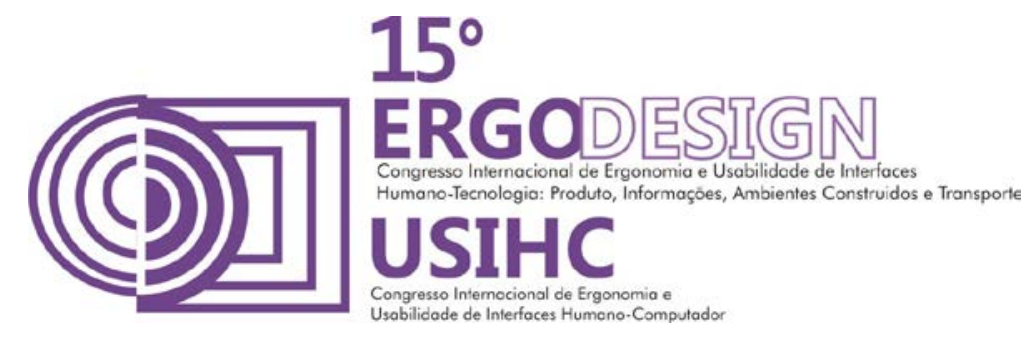

No que diz respeito aos aspectos posturais no desempenho da atividade, vimos que o funcionário desempenha suas atividades de pé em toda a jornada de trabalho, seu tronco fica constantemente fletido e seu membro superior elevado, movendo a máquina de corte. Tal assunção postural provoca desconforto, além da possibilidade de lesões aos nervos (quando somada ao fato de que a máquina apresenta um índice constante de vibração quando ligada).

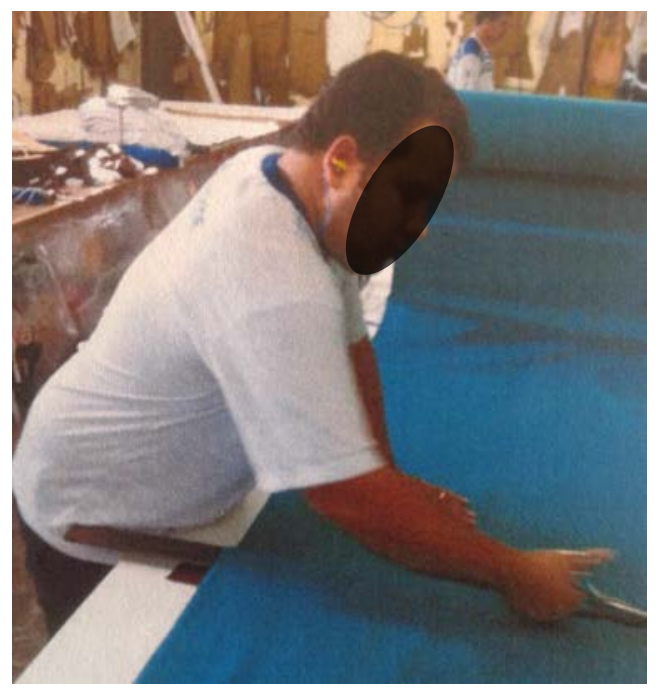

Figura 4: Assunção postural do funcionário em um dos procedimentos

Após os resultados encontrados no ambiente de corte, foi possível elaborar uma lista de recomendações ergonômicas a serem consideradas para a adequação do ambiente ao ser humano e ao trabalho nele realizado. A saber:

- Adequar o sistema de ventilação;

- Melhorar o sistema de iluminação do setor de corte, conforme a norma NBR5413;

- Adequar a iluminação do setor de corte, focando a precisão que a atividade exige;

- Adaptar as aberturas no ambiente, por meio de reforma, para que as mesmas fiquem mais próximas dos funcionários e que proporcione mais ventilação no local;

- Estudar qual o melhor tipo de ventilação artificial deve ser utilizado no ambiente e implantá-la;

- Utilizar máquinas de corte que emitam o menor nível de ruído possível;

- Reorganizar o espaço, dividindo o setor de corte do setor de estoque de tecido;

- Organizar o ambiente de corte, de modo a melhorar os fluxos, retirando as caixas de equipamentos do chão;

- Retirar as modelagens prontas que ficam penduradas na parede, para possibilitar o funcionário a transitar melhor em volta da mesa de corte; 


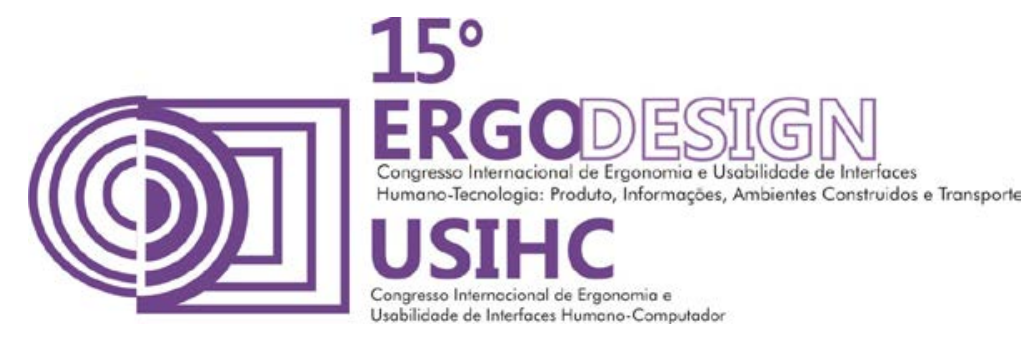

- Agrupar os elementos de apoio a atividade, de modo a facilitar a atividade feita pelo trabalhador;

- Fornecer equipamentos de segurança específicos para cada atividade, promovendo ações de incentivo a utilização dos mesmos;

- Inserir pausas na atividade de corte deste setor, uma vez que o funcionário trabalha toda sua jornada de pé.

\section{CONCLUSÕES E CONSIDERAÇÕES FINAIS}

A metodologia proposta para a realização da avaliação ergonômica do ambiente construído de corte, a MEAC, contribuiu consideravelmente para a avaliação das condições físico-ambientais do setor de corte, permitindo identificar os fatores que interferem no bem estar dos usuários do ambiente, tais como: iluminação, ventilação e aeração, vibração, ruído, temperatura, características cromáticas do local e organização do espaço (layout, fluxos, postos de trabalho e acessibilidade).

A mesma permitiu ainda conhecer o ambiente de trabalho, assim como a maneira na qual as atividades reais são desenvolvidas no local, além de realizar as medições necessárias para constatação ou não das inadequações das condições ambientais do ambiente. A partir da metodologia, foi possível verificar como os funcionários do setor percebem seu ambiente, assim como os mesmos idealizam um ambiente para a realização de suas atividades, sendo possível identificar a partir disso, os fatores que incomodam mais e menos os trabalhadores.

Através da avaliação ergonômica do ambiente construído e dos dados, valores e parâmetros apresentados no referencial teórico, foi possível constatar que todas as condições físicoambientais do setor de corte apresentavam deficiências, exceto os aspectos cromáticos. Os resultados também demonstraram que alguns desses fatores tornam o ambiente de corte extremamente prejudicial à saúde e segurança dos usuários, alterando também, na forma e velocidade com que os mesmos executam as suas respectivas atividades.

É possível também, afirmar com base nos resultados, que os fatores relacionados à ventilação, iluminação, temperatura e organização do espaço são os condicionantes físico-ambientais que detém maior atenção e preocupação, considerando que o ambiente é mal ventilado, fazendo com que o mesmo permaneça com altas temperaturas durante o período de verão e somado a falta de espaço, torna o setor quente, desconfortável, prejudicial à segurança e a saúde, gerando insatisfação por parte dos usuários do mesmo.

Em resumo, os resultados permitiram identificar divergências em diversos aspectos físicos e ambientais no setor de corte da empresa, os quais necessitam de melhorias para, então, atender as necessidades daqueles que utilizam o mesmo. Sendo assim, torna-se necessária a realização de adequações na estrutura física do setor, assim como investir na melhoria dos sistemas de iluminação e ventilação.

Desse modo, espera-se que os resultados possam mostrar e alertar os proprietários da situação real das condições de trabalho de seus funcionários, fazendo com que os mesmos adotem medidas projetos que visem adequar o ambiente de trabalho as necessidades dos seus 


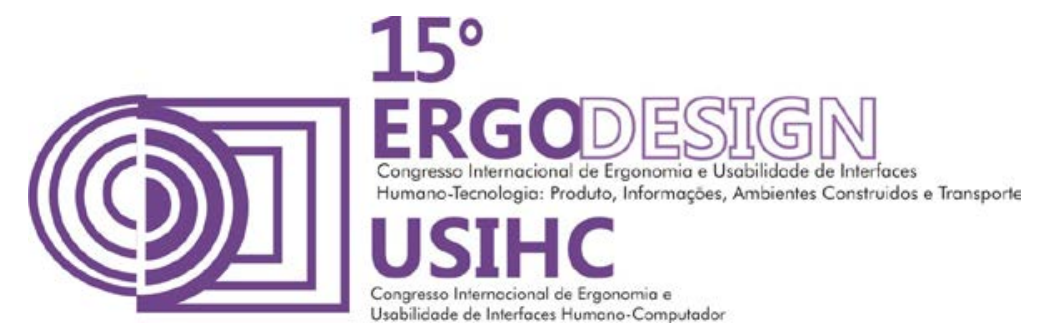

usuários, promovendo a qualidade de vida e humanizando o tratamento dos operários no ambiente de trabalho.

\section{REFERÊNCIAS BIBLIOGRAFICAS}

AQUINO, Danielly Silva de. et al. Análise da qualidade de vida no setor de costura de uma indústria de confecção. In: COMBREPRO 2011: Congresso Brasileiro de Engenharia de Produção, 1., 2011, Ponta Grossa.

ARAÚJO, G. M.; REGAZZI, R. D. Perícia e avaliação de ruído e calor passo a passo: teoria e prática. Rio de Janeiro: 2002.

ASSOCIAÇÃO BRASILEIRA DE NORMAS TÉCNICAS - NBR 10152: níveis de ruído para conforto acústico. Rio de Janeiro, $1987.4 \mathrm{p}$.

ASSOCIAÇÃO BRASILEIRA DE NORMAS TÉCNICAS - NBR 5413: iluminância de interiores. Rio de Janeiro, 1992. $13 \mathrm{p}$.

BISTAFA, Sylvio R. Acústica Aplicada ao Controle do Ruído. São Paulo, editora Edgard Blücher, 2006. BRASIL. Fundacentro. Ruído. Disponível em: http://www.fundacentro.gov.br. Acesso em: 8 mar. 2013b.

BRASIL. Ministério do Trabalho e Emprego. 2007. NR 17 - Ergonomia (117.000-7). Disponível em:<http://www.mte.gov.br/legislacao/normas_regulamentadoras/nr_17.asp>. Acesso em: 11 set. 2012.

CONSELHO E SEGURANÇA DO TRABALHO. O que é vibração? 2011. Acesso em: http://conselhoeseguranca.blogspot.com.br. Acesso em: 27 mar. 2013.

DIEESE - Departamento Intersindical de Estatística e Estudos Socioeconômicos. Relatório final: Diagnóstico do setor têxtil e de confecções de Caruaru e região. 2010. Disponível em: http://www.dieese.org.br. Acesso em: 17 nov. 2012.

IBGE - Instituto Brasileiro de Geografia e Estatística. IBGE Cidades: Dados gerais: Caruaru. Disponível em: http://www.ibge.gov.br. Acesso em: 17 ago. 2013.

IIDA, Itiro. Ergonomia: projeto e produção. 2a edição. São Paulo: Edgard Blucher, 2005.

LAMBERT, Roberto, DUTRA, Luciano, PEREIRA, Fernando O. R. Eficiência Energética na Arquitetura. São Paulo: PW, 1997.

MONTENEGRO, Gildo. Ventilação e cobertas: estudo teórico, histórico e descontraído. São Paulo: Edgard Blucher, 2003.

SEBRAE - Serviço Brasileiro de Apoio às Micro e Pequenas Empresas. Comece certo: indústria de confecção. 2004. pág. 5. Disponível em: http://www.sebrae.com.br. Acesso em: 22 mai. 2012.

SEBRAE - Serviço Brasileiro de Apoio às Micro e Pequenas Empresas. Cadeia produtiva têxtil e de confecções: Cenários econômicos e estudos setoriais. 2008. Disponível em: http://www.sebrae.com.br. Acesso em: 22 mai. 2010.

STONE, N. J. Designing effective study environments. Journal of Environmental Psychology, v.21, p.179-190, 2001. 


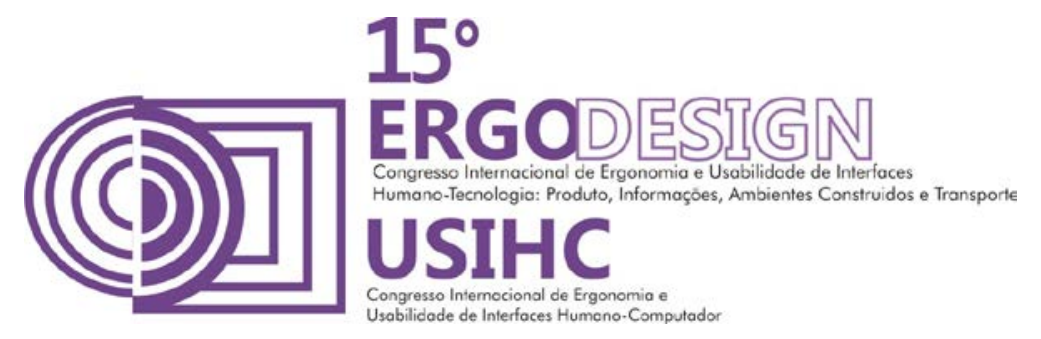

VASCONCELOS, Christianne Soares Falcão e; Villarouco, Vilma; Soares, Marcelo Márcio. Avaliação Ergonômica do Ambiente Construído: Estudo de caso em uma biblioteca universitária. In: Ação Ergonômica, v. 1, n. 1, 2009.

VILLAROUCO, V. O ambiente está adequado? Anais do ENEAC 2007: I Encontro Nacional de Ergonomia do Ambiente Construído e II Seminário Brasileiro de Acessibilidade Integral. Recife, 2007.

VILLAROUCO, Vilma. An ergonomic look at the work environment. In: Proceeding from IEA 09: 17th World Congress on Ergonomics. China: Beijing, 2009.

VILLAROUCO, Vilma; ANDRETO, Luiz. F. M. Avaliando desempenho de espaços de trabalho sob o enfoque da ergonomia do ambiente construído. In: Produção, v. 18, n. 3, p. 523-539, 2008. 